\title{
Gestão financeira de uma cooperativa agroindustrial: práticas de gerenciamento e análise financeira
}

\author{
Financial management of a cooperative agro industry: practice management and fi- \\ nancial review
}

\begin{abstract}
Resumo
As demonstrações contábeis têm a função de auxiliar os gestores e usuários da informação contábil no processo de tomada de decisão. O cooperativismo tem tomado cada vez mais destaque no Sistema Financeiro Nacional. Esse artigo tem como objetivo analisar e demonstrar o desempenho econômico e financeiro de uma Cooperativa Agroindustrial de Santa Catarina na cidade de Chapecó. A análise teve como base as demonstrações contábeis, balanço patrimonial e demonstração de sobras ou perdas da cooperativa, entre os anos de 2012 e 2014. Para alcançar o objetivo foi realizada uma pesquisa exploratória e qualitativa nas demonstrações da cooperativa estudada. Sabendo-se disso, é sugerido que os aspectos de acompanhamento, controle, avaliação e aprimoramento dos resultados são de elevada importância, pelo fato de várias cooperativas não proporcionarem adequada atenção, o qual deve ser controlado em tempo real com o planejamento estratégico.
\end{abstract}

Palavras-chave: Cooperativismo; Gestão de cooperativas; Análise financeira.

\begin{abstract}
The financial statements are meant to help managers and users of accounting information in the decisionmaking process. The cooperative has taken more prominence in the financial system. This article aims to analyze and demonstrate the economic and financial performance of an Agroindustrial Cooperative of Santa Catarina in the city of Chapecó. The analysis was based on the financial statements, balance sheet and statement of leftovers or cooperative losses, between the years 2012 and 2014. To achieve the goal and an exploratory qualitative research was carried out in the statements of the studied cooperative. Knowing this, it is suggested that aspects of monitoring, control, evaluation and improvement of the results are of great importance, because many cooperatives do not provide adequate care, which must be controlled in real time with strategic planning.
\end{abstract}

Key-words: Cooperatives; Cooperative management; Financial analysis.

Recebido: 19/04/2015 Aceito: 17/06/2015

Alan César Souza Maciel ${ }^{1}$, Ana Paula Anziliero Hermes ${ }^{1}$, Fabrício Bagnara ${ }^{1}$, Diego Bilibio ${ }^{1}$, Roger Natan de Lima ${ }^{1}$ e Enise Barth-Teixeira ${ }^{2}$

${ }^{1}$ Estudantes de Graduação em Administração. Universidade Federal da Fronteira Sul - campus de Chapecó.

2 Professora, Doutora em Engenharia de Produção, curso de Administração. Universidade Federal da Fronteira Sul. 


\section{Introdução}

$\mathrm{C}$ omo define a Organização das Cooperativas Brasileiras (2013), o cooperativismo é "um movimento, filosofia de vida e modelo socioeconômico capaz de unir desenvolvimento econômico e bem-estar social", assim, possui alguns princípios que possibilitam efetivar esse conceito e se destacar com relação a outros tipos de organizações e, possui também, classificações quanto ao ramo de serviço ou produto.

O cooperativismo, como todo sistema econômico, desde seu surgimento passou por várias mudanças que se deram a partir de tentativas e erros. Hoje, se tornou um modo de economia que promove a igualdade e contribui para um mercado mais justo buscando também dar oportunidades a todos.

A Cooperativa $X$ surgiu em decorrência da necessidade de auxiliar os pequenos e médios produtores rurais em busca de valorização do seu trabalho, bem como, uma remuneração mais justa. A cooperativa tem como atividade central a armazenagem e comercialização da produção agrícola dos seus associados, como o trigo, feijão, soja e milho. Sendo que, realiza a industrialização da soja e milho, além da produção de ração agregando valor a produção agrícola dos associados da cooperativa, visando melhorar a produção e trabalho, mas principalmente a qualidade de vida dessas famílias rurais, investindo constantemente em novas tecnologias e técnicas.

O tema da presente pesquisa é a gestão financeira em uma cooperativa de grande representatividade na Região Oeste de Santa Catarina, para isso, o objeto a ser pesquisado será uma Cooperativa Agroindustrial, que neste trabalho se deu o nome de Cooperativa $\mathrm{X}$. O problema de pesquisa estudado é: como se desenvolve a gestão financeira de uma cooperativa que apresenta considerável importância para o desenvolvimento regional?

O objetivo do estudo é entender o modo de gestão financeira a partir de demonstrativos contábeis e administrativos.

O desenvolvimento deste trabalho tem a intenção de analisar os dados financeiros da cooperativa, fornecendo compreensão dos lucros, das perdas e das sobras, sua participação dentro do setor econômico que integram a sociedade e os colaboradores.

Fundada em outubro de 1967, a Cooperativa em estudo surgiu no mercado para atender uma grande necessidade: a busca dos pequenos e médios produ- tores rurais por uma remuneração mais justa e a valorização do seu trabalho. A atividade central da cooperativa é a comercialização e armazenagem da produção agrícola dos associados, como milho, soja, feijão e trigo.

A escolha da cooperativa justifica-se pelo fato desta ser referência quando se fala em cooperativas. A Cooperativa $X$ exerce influência na vida de muitas famílias, as quais se associam à mesma com o objetivo de obter o sustento de forma cooperada. Sendo assim, é de elevado interesse, conhecermos a situação financeira desta que é uma das maiores cooperativas da região, saber dos seus resultados e o destino de seus rendimentos e desta forma saber como funciona a distribuição dos lucros obtidos.

\section{Referencial teórico}

Com o intuito de aprofundar o conhecimento sobre o tema estudado desenvolveu-se a pesquisa bibliográfica iniciando pelo cooperativismo e gestão de cooperativas, em seguida foi estudado a gestão financeira em cooperativas e indicadores financeiros, e por fim a avaliação dos resultados nas cooperativas.

\subsection{Cooperativismo}

Para Frantz (2012), através do cooperativismo é possível mudar o modelo capitalista de organização que a sociedade está sujeita. O cooperativismo é um movimento que acontece ao redor do mundo todo, capaz de unir o desenvolvimento econômico com o bem-estar das pessoas e necessita da colaboração e associação de pessoas com os mesmos interesses e tem como principais referências a participação democrática, a solidariedade, a independência e a autonomia.

Segundo a Organização das Cooperativas Brasileiras (OCB, 2014), o cooperativismo é tido como a forma ideal de organização. É o modelo socioeconômico que tem a capacidade de unir o desenvolvimento econômico e o bem-estar social. Tem como fundamento a união de pessoas e não o capital e segue os princípios da solidariedade, participação democrática, autonomia e independência.

O cooperativismo tem sete princípios básicos que são adotados e seguidos pelas cooperativas, de acordo com a OCB (2014), são eles: Adesão voluntária e livre; Gestão democrática; Participação eco- 
nômica dos membros; Autonomia e independência; Educação, formação e informação; Intercooperação; Interesse pela comunidade.

Schmidt e Perius (2003) afirmam que, seguindo esses princípios, as cooperativas levam os seus valores a prática. Assim, o cooperativismo tem sido a resposta aos problemas impostos pela globalização.

O aparecimento do cooperativismo está diretamente associado às iniciativas dos trabalhadores contra a opressão social. O cooperativismo é tido através da união entre pessoas com um objetivo comum. No Brasil a cooperação é vista desde a época da colonização portuguesa. Através do Movimento Cooperativista Brasileiro que surgiu no final do século 19, com a união de funcionários públicos, profissionais liberais, militares e operários que juntos lutavam para ter suas necessidades atendidas, o cooperativismo ganhou força no país (OCB, 2014).

Conforme a OCB (2014), nos dias de hoje existem mais de 6.500 cooperativas no Brasil, com 10 milhões de associados em treze setores da economia: agropecuário, educacional, de trabalho, produção, saúde, consumo, habitacional, mineração, transporte, turismo e lazer, infraestrutura, especiais e de crédito.

Para a cooperativa tomar sua forma legal, é necessária a associação de no mínimo 20 pessoas unidas através de um objetivo comum de caráter econômico. A constituição de uma cooperativa ocorre de forma livre, além disso, podem organizar suas atividades econômicas para acessar o mercado tendo sempre como base os princípios e valores da solidariedade, ajuda mútua, honestidade, democracia e participação (MINISTÉRIO DA AGRICULTURA, 2014).

\subsection{Gestão de cooperativas}

Com as constantes mudanças econômicas, culturais e sociais, fazem com que as empresas e cooperativas desenvolvam novos modelos de gestões, utilizando modernos instrumentos administrativos. Esses métodos utilizados variam de acordo com a realidade e as necessidades de cada organização.

Entretanto, não pode esquecer que esse processo de adequação é fundamental para a qualidade final de aplicação do modelo, pois executivos e profissionais da cooperativa serão obrigados a analisar e a pensar fortemente a respeito do modelo de gestão e de cada uma de suas partes componentes. (OLIVEIRA, 2011, p. 41)
Modelo de gestão voltado a cooperativas é conceituado como o processo interativo e consolidado de desenvolver as atividades de Planejamento, Organização, Direção e Avaliação, com foco no desenvolvimento e oportunidades de mercado para a cooperativa (OLIVEIRA. 2011).

Para aprimorar a funcionalidade do modelo de gestão, as cooperativas devem procurar o desenvolvimento da forte cultura organizacional, que engloba a formação de valores, mecanismos e integrações e outras áreas que desencadeiam em uma reação para as constantes mudanças no mercado global competitivo.

Para o modelo de gestão funcionar os conhecimentos e as estratégias da cooperativa devem ser amplamente compartilhados e debatidos, valorizando a cooperação e não a competição entre cooperados, tornando essencial o desenvolvimento de novas capacidades de aprendizado, visando o trabalho em equipe como uma necessidade básica, pelo fato dos cooperados precisarem de todos para poder agir coletivamente com o intuito de melhorar suas capacidades e consolidar os processos de mudanças.

Em contrapartida, o alto escalão das cooperativas devem ter seus esforços direcionados ao aumento dos lucros/sobras e não a redução dos custos. Concentrando-se na eliminação da restrição para o lucro/sobra, o que consequentemente acaba impedindo a cooperativa de ganhar mais e ter resultados interessantes.

A situação de o modelo de gestão provocar mudanças cooperativas deve ser considerada um processo sem fim. Isso porque, com base nas mudanças efetuadas, novos problemas devem surgir, o que exigirá novas soluções, as quais podem necessitar de novas abordagens de modelos de gestão. Naturalmente, esse processo não pode ser sintomático, mas sistemático, gradativo e acumulativo. (OLIVEIRA, 2011, p. 55)

Para o adequado desenvolvimento e aplicação do modelo de gestão na cooperativa, devem focar a amplitude global da cooperativa, sustentar o modelo de gestão com todos os sistemas e instrumentos, ter a metodologia correta, expandir barreiras, buscando a constante qualidade total. Porém para ser posta em prática o modelo de gestão, exige certa flexibilidade da cooperativa, para poder ser aplicada em diferentes situações que a cooperativa poderá encontrar no seu cotidiano. 


\subsection{Gestão financeira nas cooperativas}

A partir da análise financeira e econômica, há possibilidade de estudar-se de forma mais detalhada a respeito dos conceitos a serem aplicados na estratégia que a cooperativa irá adotar para gerir e buscar seus resultados, onde estão envolvidos planejamento de longo e médio prazo os quais são conhecidos através da análise econômica e financeira.

Os resultados das cooperativas devem ser averiguados detalhadamente e comparados com os dados anteriormente obtidos ao longo do tempo, após a exploração e a interpretação dos resultados se torna possível o direcionamento da cooperativa para realizar as ações corretas, toda a análise de resultado deve ser repassada aos cooperados de uma maneira objetiva e simples para que haja fácil compreensão do que acontece na cooperativa, contudo, a análise a ser feita não é uma tarefa de simples execução e exige de quem a realiza, conhecimento amplo e aprofundado na área de mercado financeiro, contabilidade gerencial e cooperativismo (CARVALHO, 2011).

De acordo com Carvalho (2011, p. 191) para que se faça a decisão mais acertada,

As cooperativas devem possuir um bom departamento contábil que demonstre, de forma clara e objetiva, a realidade dos fatos. Os números traduzem tendências, influenciando diretamente as ações. Para a boa aceitação das demonstrações financeiras na tomada de decisão, é preciso que elas expressem, de forma objetiva, o panorama geral da cooperativa, sendo de fácil entendimento para os dirigentes tomarem decisões.

Para a gestão financeira de uma cooperativa ser realizada existe diversas fórmulas para calcular os índices e permitir que sejam analisados os dados da organização, porém, deve-se ter uma visão ampla do crescimento desse setor do qual faz parte a cooperativa para que haja parâmetros aceitáveis considerando um desenvolvimento padrão. Dessa forma, os dados que foram obtidos precisam de um tratamento especial para sua interpretação, já que, o objetivo real das cooperativas não está visando lucros financeiros, mas sim a valorização das pessoas. Apesar das cooperativas não visarem lucros, elas não podem aceitar ter prejuízos constantes, pois isso afeta seus cooperados financeiramente (CARVALHO, 2011).
Os indicadores financeiros nos permitem observar índices numéricos e a partir disso, analisar e discutir os resultados financeiros de determinada empresa, neste caso a cooperativa.

Na visão de Ross, Westerfiled, Jordan observase o seguinte:

Esses índices consistem em ferramentas de comparação e investigação das relações entre diferentes informações financeiras. A seguir, discutiremos os índices mais comuns, mas há muitos outros que sequer mencionaremos. Um dos problemas com o uso dos índices consiste em no fato de que pessoas distintas e publicações diferentes não os calculam da mesma forma, e isso leva a grande confusão (ROSS, WESTERFILED, JORDAN, 2011, p. 80).

Análise horizontal trata de evidenciar a evolução de uma conta ou grupo em determinado período, já a analise vertical evidência a representatividade de uma conta ou grupo num total, ou seja, a sua participação num grupo total de montante.

Na visão de Braga, pode ser encontrada a seguinte definição:

Analise horizontal é realizada a partir de um conjunto de balanços e demonstrações de resultado consecutivos. Para cada elemento desses demonstrativos são calculados números-índices, cuja base corresponde ao valor mais antigo da série. Desse modo, pode-se avaliar a evolução de cada elemento patrimonial e de resultado ao longo de diversos períodos consecutivos (BRAGA, 2011, p. 143).

A análise vertical é aplicada sobre o balanço patrimonial, a demonstração do resultado e demonstrações das origens e aplicações financeiras. No balanço, a analise vertical fornece indicadores que facilitam a avaliação da estrutura do ativo e das suas fontes de financiamento. Esses indicadores correspondem às participações percentuais dos saldos das contas e dos grupos patrimoniais sobre o total do ativo (ou do passivo + patrimônio líquido) (Braga, 2011, p. 145).

Braga (2011) e Ross, Westerfiled e Jordan (2011), mostram alguns indicadores, os quais serão de suma importância para a nossa análise, e estão descritos de forma breve o que cada um significa e como deve ser aplicado.

\section{Índices de liquidez}

Índices de Liquidez, apesar de terem outros índices essa análise trouxe apenas os que evidenciamos ser os mais importantes.

\subsection{Indicadores financeiros}


Liquidez corrente: $\mathrm{AC} / \mathrm{PC}=$ Capacidade da empresa em pagar as dívidas de curto prazo com ativos de curto prazo.

Liquidez imediata: disponível/PC = Capacidade de a empresa pagar suas dívidas de curto prazo com disponível imediato, dinheiro.

\section{Índices de estrutura de capital}

Participações de terceiros nos totais: exigível total/ Ativo = Quanto do capital de terceiros está financiando o ativo da empresa.

Composição do endividamento: PC/Exigível total $=$ Quanto da dívida é de curto prazo

\section{Grau de Alavancagem Financeira}

Gaf: ROA/ROE, demonstra o quanto a empresa está alavancada.

Retorno sobre ativos (ROA): lucro operacional/ativo total $=$ Retorno dos ativos.

Rentabilidade do capital próprio (ROE): lucro líquido/PL = Quanto de lucro os sócios obtêm para cada 1 real investido

\section{Índices de lucratividade}

Margem líquida: resultado líquido/ receita líqui$\mathrm{da}=$ quanto que a empresa tem de lucro para cada 1 real vendido.

Margem operacional: resultado operacional/ receita liquida = quanto a empresa tem de resultado operacional para cada 1 real vendido.

\section{Índices de rentabilidade}

Retorno sobre ativos (ROA): lucro operacional/ativo total $=$ Retorno dos ativos.

Rentabilidade do capital próprio (ROE): lucro líquido/PL = Quanto de lucro os sócios obtêm para cada 1 real investido

\subsection{Avaliação dos resultados nas cooperativas}

Para Oliveira (2011), aspectos de acompanhamento, controle, avaliação e aprimoramento dos resultados são de elevada importância para as cooperativas, inclusive porque muitas cooperativas não proporcionam adequada atenção a esse processo, o qual deve ser, idealmente, um autocontrole em tempo real com o planejamento estratégico.
O mesmo autor define avaliação nas cooperativas da seguinte forma:

Avaliação é a função do processo administrativo das cooperativas que, mediante a comparação com padrões previamente estabelecidos, procura medir, controlar e avaliar o desempenho e o resultado das estratégias, projetos e ações, com a finalidade de realimentar os tomadores de decisões, de forma que possam corrigir ou reforçar esse desempenho ou interferir em outras funções do processo administrativo das cooperativas, para assegurar que os resultados satisfaçam as metas e aos objetivos estabelecidos (OLIVEIRA, 2011, p. 282).

Segundo Carvalho (2011), é possível realizar estudos aprofundados sobre a aplicação de conceitos a serem seguidos, a partir da análise econômica e financeira, adotando assim, posturas estratégicas que podem direcionar a cooperativa para o resultado. Toda estratégia envolve planejamento de médio e longo prazo, pontos impossíveis de conhecer sem a análise econômica e financeira.

$\mathrm{O}$ autor ainda afirma que as cooperativas devem apurar detalhadamente os resultados, comparandoos com dados históricos obtidos ao longo do tempo. Dessa forma, é possível direcionar as cooperativas para a ação correta a partir do conhecimento e interpretação dos resultados.

Os indicadores de desempenho e avaliação dos resultados das cooperativas devem ser estabelecidos de maneira estruturada, para que possam ser entendidos e aceitos por todos os envolvidos, representados principalmente pelos cooperados e pelos executivos e funcionários da cooperativa (OLIVEIRA, 2011).

Em uma pesquisa realizada por Lopes (2009), com o objetivo de investigar a importância dos indicadores socioeconômicos na natureza da gestão das cooperativas agropecuárias da região central do Rio Grande do Sul, concluiu-se que no período analisado de 2003 a 2008, as cooperativas agropecuárias apresentaram características de sucesso em suas administrações, conforme resultados obtidos de seus indicadores. Com base nos indicadores analisados os dirigentes, diretores, associados, e sociedade organizada puderam desenvolver avaliações sobre as sociedades cooperativas agropecuárias levando em consideração os princípios do cooperativismo, a transparência administrativa, a responsabilidade social e a sua sustentabilidade.

Em outro estudo realizado por Gozer et al (2007), avaliou-se a situação econômico-financeira 
de uma cooperativa agropecuária de grande porte do estado do Paraná utilizando índices-padrão do setor, ao final do trabalho constatou-se que a construção de índices-padrão para o ramo do cooperativismo agropecuário serve de ferramenta para posicionar a cooperativa dentro do seu setor de atividade, o que faz com que a avaliação econômicofinanceira se torne mais precisa.

Brito et al (2012) realizaram uma análise financeira a partir do balanço financeiro de outra cooperativa agroindustrial do Paraná referente aos períodos 2009 e 2010 com objetivo de identificar sua situação financeira. Os autores analisaram os índices de estrutura de capital, de liquidez e de rentabilidade, que se tornam ferramentas concisas quando cruzadas com a demonstração do resultado do exercício e o balanço patrimonial, concluindo que a situação financeira da empresa está nos padrões atribuídos aos índices conforme a teoria.

Algumas sugestões para as cooperativas consolidarem um adequado processo de avaliação são apresentadas por Oliveira (2011): a interação com o sistema de informações, a identificação dos momentos de realização da avaliação, a interligação entre os diferentes níveis de avaliação, a existência de diferentes formas de análise de consistência, a adequada relação custos e benefícios, o otimizado nível de conhecimento, participação e comprometimento, a adequada administração das resistências e da cultura organizacional, bem como a existência de qualidade total no processo de avaliação de resultados e do modelo de gestão das cooperativas.

Carvalho (2011) ainda destaca a importância da avaliação do desempenho nas cooperativas, já que os resultados obtidos mediante a aplicação de sistemas de desempenho fazem com que as cooperativas se voltem para as potenciais ações que criam diferencial competitivo, identificando tendências futuras.

\section{Metodologia}

Do ponto de vista de sua natureza, essa pesquisa se classifica como sociais aplicadas que de acordo com Vergara (2013, p.47) esta pesquisa é "fundamentalmente motivada pela necessidade de resolver problemas concretos, mais imediatos ou não".

A pesquisa realizada se classificou como um estudo de caso qualitativo, o estudo se deu por meio de pesquisa bibliográfica, que segundo Marconi e Lakatos (2010, p.183), consiste em:

Toda bibliografia já tornada pública em relação ao tema de estudo, desde publicações avulsas, boletins, jornais, revistas, livros, pesquisas, monografias, teses, material cartográfico etc., até meios de comunicação orais: rádio, gravações em fita magnética e audiovisuais: filmes e televisão.

Segundo Vergara (2013), a pesquisa bibliográfica é o desenvolvimento de um estudo sistematizado com embasamento em material publicado em revistas, redes eletrônicas, livros ou jornais, ou seja, materiais que são acessíveis ao público em geral. Fornecendo ainda instrumentos para análise de qualquer outro tipo de pesquisa, sendo que esse também pode se esgotar em si mesmo.

A abordagem desta pesquisa se classifica como qualitativa, a qual segundo Gerhardt e Silveira (2009), não se preocupa com representatividade numérica, mas, sim com o aprofundamento da compreensão de um grupo social, de uma organização, etc. A pesquisa qualitativa considera a existência de relação dinâmica entre o mundo real e o sujeito, ou seja, "um vínculo indissociável entre o mundo objetivo e a subjetividade do sujeito que não pode ser traduzido em números. " (PRODANOV; FREITAS, 2013, p. 70).

Em relação aos procedimentos, este trabalho fez o uso de duas técnicas: a pesquisa bibliográfica e a documental. Sendo a primeira caracterizada por Prodanov e Freitas (2013, p. 54):

Quando elaborada a partir de material já publicado, constituído principalmente de: livros, revistas, publicações em periódicos e artigos científicos, jornais, boletins, monografias, dissertações, teses, material cartográfico, internet, com o objetivo de colocar o pesquisador em contato direto com todo material já escrito sobre o assunto da pesquisa.

Já a pesquisa documental é definida como uma pesquisa baseada em materiais que ainda não receberam um tratamento analítico ou que podem ser refeitos de acordo com os objetivos da pesquisa (GIL, 2008).

Ainda em relação à pesquisa documental Vergara $(2013$, p. 43), define que a investigação ou pesquisa documental se dá por meio de:

Documentos conservados no interior de órgãos públicos e privados de qualquer natureza, ou com pessoas: registros, anais, regulamentos, circulares, ofícios, memoran- 
dos, balancetes, comunicações informais, filmes, microfilmes, fotografias, vídeoteipe, dispositivos de armazenagem por meio ópticos, magnéticos e eletrônicos em geral, diários, cartas pessoais e outros.

Finalmente, a análise de dados, que segundo Marconi e Lakatos (2010, p. 151) "é o processo de formação de sentido além dos dados, e esta formação se dá consolidando, limitando e interpretando o que as pessoas disseram e o que o pesquisador viu e leu, isto é, o processo de formação de significado", dessa forma, os dados foram explicados conforme as relações existentes entre o objeto estudado e os demais elementos afetados pela sua existência.

\section{Resultados e discussões}

Esta etapa da pesquisa refere-se à análise e discussão dos resultados obtidos, inicialmente é apresentado a cooperativa e seus princípios, em seguida é demonstrado as formas de gestão e políticas financeiras da cooperativa, e por último é demonstrado e discutido os seus resultados financeiros.

\subsection{A cooperativa}

Na década de 70, uma das primeiras cooperativas de Chapecó-SC uniu-se a outras cooperativas da região, formando a Cooperativa $\mathrm{X}$, uma cooperativa singular, agropecuária mista, que atualmente regese por estatuto próprio e disposições legais vigentes, com sede em Chapecó-SC e tendo como ano social compreendido entre primeiro de janeiro a 31 de dezembro do mesmo ano.

As atividades desenvolvidas pela cooperativa compreendem:

- Comercialização e armazenagem da produção agrícola dos associados, como milho, soja, feijão e trigo;

- Industrialização de trigo e soja, e a fabricação de farinha e rações para agregar valor a produção agrícola dos cooperados;

- Produção de sementes certificadas, como soja, feijão, trigo e cobertura de solo.

- Desenvolve parcerias com outras cooperativas para o beneficiamento de citros, suínos, aves e leite.

A cooperativa conta com cerca de 15 mil famílias associadas, sendo mais de $85 \%$ inseridas na economia familiar, distribuídas em 80 municípios catarinenses e alguns no Paraná. A cooperativa também se preocupa com questões ambientais em suas estruturas.

Contudo, a Cooperativa X surgiu com o intuito de atender a necessidade de busca dos pequenos e médios produtores rurais por uma remuneração mais justa e a valorização do seu trabalho. Para isso definiu sua missão e projetou sua visão, tudo isso orientados pelos valores da cooperativa:

Missão: Promover o desenvolvimento sustentável do setor agropecuário, gerando resultados econômicos e sociais para a sociedade.

Visão: Ser referência nacional como cooperativa agropecuária.

Valores: integridade; credibilidade; atuação coletiva; empreendedorismo; sustentabilidade.

Para atender a missão proposta, a cooperativa conta com um processo consolidado para desenvolver as atividades de planejamento, organização e direção. Com foco no desenvolvimento e oportunidades de mercado, a cooperativa possui um modelo de gestão adequada ás suas necessidades.

\subsection{Gestão e políticas financeiras da coope- rativa}

Conforme estatuto próprio, a Cooperativa X é administrada por um conselho de administração, composto por 10 conselheiros, sendo formado pela diretoria executiva (presidente e dois vicepresidentes), secretário e seis conselheiros. Dentre as diversas atribuições que compete ao conselho de administração, as que envolvem a gestão financeira são:

- Planejar, estabelecer normas e controlar os resultados das operações e serviços da cooperativa;

- Determinar valores a serem destinados a cobrir as despesas dos serviços da sociedade;

- Avaliar e providenciar o montante dos recursos financeiros e dos meios necessários ao atendimento das operações e serviços;

- Estimar previamente a rentabilidade das operações e serviços, bem como a viabilidade;

- Fixar o montante de gastos gerais em orçamento anual que indique a fonte de recursos para a respectiva cobertura;

- Estabelecer as normas de controle das operações e serviços, verificando mensalmente, no mínimo, o estado econômico-financeiro da cooperativa e o desenvolvimento das operações e ativi- 
dades em geral, por meio de informações contábeis e gerenciais específicas.

Por se tratar de uma cooperativa, e consequentemente não possuir fins lucrativos, a Cooperativa $\mathrm{X}$ não possui distribuição de dividendos, dessa forma, o capital social da cooperativa é dividido em cotas-partes, denominada cota-capital, variando sua quantidade conforme o número que for subscrito. A formação do capital social se dá por subscrição e integralização de capital em proporções regida pelo estatuto.

Para fins de aumento permanente do capital social, a Cooperativa $X$ faz acréscimos e retenções de capital por meio de capitalização de $1 \%$ sobre o valor de fornecimento de insumos e de repasse de produtos agropecuários, a ser integralizado à cotacapital do associado.

A devolução da cota-capital se dá considerando sempre a idade do titular associado, em termos gerais, a restituição do capital é realizada após completar 60 anos de idade para homens e 55 para mulheres, ou sendo associado há mais de dez anos, o mesmo pode requerer restituição de $60 \%$ da cotacapital.

O balanço geral, incluindo o confronto dos ingressos e dispêndios são levantados no último dia de cada ano por meio das demonstrações contábeis elaboradas de acordo com as normas aplicadas às sociedades cooperativas. As sobras líquidas apuradas no exercício, depois de deduzidos os percentuais para fundos e reservas, são rateados entre os associados em partes diretamente proporcionais ao movimento econômico de cada um dos associados.

$\mathrm{O}$ crescimento econômico e financeiro é necessário para qualquer empresa se manter no mercado, de acordo com o Presidente, a Cooperativa vem apresentando crescimento acima de índices nacionais, proporcionando solidez à cooperativa, prestando um bom serviço ao seu quadro social e agregando valor na sua produção.

No entanto o crescimento financeiro tem proporcionado o aumento das sobras que são distribuídas na forma de cota-capital, o que não é objetivo da cooperativa que não possui fins lucrativos. Segundo o presidente, esta não é uma preocupação atual, porém é necessário adotar práticas de gerenciamento para conter esse aumento nos lucros.

\subsection{Análise financeira}

As análises verticais e horizontal realizadas conforme proposto por Braga (2011) permitiu a análise de investimentos e financiamento da Cooperativa $\mathrm{X}$, por meio dos resultados que estão apresentados na Tabela 1.

Tabela 1 - Análise vertical e horizontal da Cooperativa X.

\begin{tabular}{lcccc}
\hline Conta contábil & $\begin{array}{c}\text { Análise } \\
\text { vertical } \\
\mathbf{2 0 1 2}\end{array}$ & $\begin{array}{c}\text { Análise } \\
\text { vertical } \\
\mathbf{2 0 1 3}\end{array}$ & $\begin{array}{c}\text { Análise } \\
\text { vertical } \\
\mathbf{2 0 1 4}\end{array}$ & $\begin{array}{c}\text { Análise } \\
\text { horizontal } \\
\mathbf{2 0 1 3 - 2 0 1 4}\end{array}$ \\
\hline Caixa e equivalentes de caixa & $7 \%$ & $7 \%$ & $12 \%$ & $66 \%$ \\
Créditos a receber & $22 \%$ & $25 \%$ & $19 \%$ & $-18 \%$ \\
Créditos de estoques & $8 \%$ & $6 \%$ & $2 \%$ & $-69 \%$ \\
Estoques & $16 \%$ & $14 \%$ & $15 \%$ & $14 \%$ \\
Aplicações a curto prazo & $1 \%$ & $2 \%$ & $\mathbf{2} \%$ & $18 \%$ \\
Despesas antecipadas & $0 \%$ & $0 \%$ & $0 \%$ & $-20 \%$ \\
Bens para revenda & $0 \%$ & $0 \%$ & $0 \%$ & $67 \%$ \\
\hline Ativo circulante & $\mathbf{5 5 \%}$ & $\mathbf{5 4 \%}$ & $\mathbf{5 0 \%}$ & $\mathbf{- 2 \%}$ \\
\hline
\end{tabular}




\begin{tabular}{|c|c|c|c|c|}
\hline $\begin{array}{l}\text { Continuação } \\
\text { Realizável a longo prazo }\end{array}$ & $1 \%$ & $2 \%$ & $3 \%$ & $71 \%$ \\
\hline Investimentos & $11 \%$ & $12 \%$ & $11 \%$ & $3 \%$ \\
\hline Imobilizado & $32 \%$ & $32 \%$ & $35 \%$ & $15 \%$ \\
\hline Intangível & $0 \%$ & $1 \%$ & $1 \%$ & $17 \%$ \\
\hline Ativo não circulante & $45 \%$ & $46 \%$ & $50 \%$ & $15 \%$ \\
\hline Obrigações com fornecedores e prest. Serviços & $13 \%$ & $12 \%$ & $9 \%$ & $-20 \%$ \\
\hline Contas e títulos a pagar e apropriar & $1 \%$ & $0 \%$ & $1 \%$ & $77 \%$ \\
\hline Obrigações com instituições financeiras & $8 \%$ & $10 \%$ & $14 \%$ & $53 \%$ \\
\hline Obrigações sociais e tributárias & $1 \%$ & $1 \%$ & $1 \%$ & $6 \%$ \\
\hline Obrigações com clientes e associados & $7 \%$ & $9 \%$ & $4 \%$ & $-58 \%$ \\
\hline Obrigações de capital & $0 \%$ & $0 \%$ & $0 \%$ & $-36 \%$ \\
\hline Provisões trabalhistas e fiscais & $1 \%$ & $1 \%$ & $1 \%$ & $-3 \%$ \\
\hline Passivo circulante & $31 \%$ & $33 \%$ & $29 \%$ & $-6 \%$ \\
\hline Obrigações com fornecedores e Prest. Serviços & $0 \%$ & $0 \%$ & $0 \%$ & $-59 \%$ \\
\hline Empréstimos e financiamentos & $14 \%$ & $13 \%$ & $12 \%$ & $0 \%$ \\
\hline Outras obrigações de longo prazo & $6 \%$ & $7 \%$ & $7 \%$ & $4 \%$ \\
\hline Passivo não circulante & $20 \%$ & $20 \%$ & $19 \%$ & $1 \%$ \\
\hline Patrimônio líquido & $49 \%$ & $48 \%$ & $52 \%$ & $15 \%$ \\
\hline
\end{tabular}

Observa-se que a política de investimentos da cooperativa foi investir em ativos imobilizados, em igual proporção nos anos de 2012 e 2013 e ainda aumentou no ano 2014, destacando também o investimento em créditos a receber e estoques que proporcionaram mais investimentos em ativos circulantes.

Em relação à política de financiamento, pode-se destacar que a forma que mais financiou a cooperativa foi o capital próprio, representando $52 \%$ das fontes de financiamento no último ano. Além do capital próprio, a cooperativa buscou recursos principalmente com instituições financeiras no curto prazo em 2014 e com empréstimos e financiamentos no longo prazo em todos os anos.
A análise horizontal mostra que nos últimos anos, em relação aos ativos, a conta que teve maior crescimento foi o realizável a longo prazo, destacase também o aumento de $67 \%$ na conta bens para revenda e o decréscimo de $69 \%$ em créditos de estoques.

Relacionado ao crescimento das fontes de financiamento, destaca-se o aumento das contas e títulos a pagar e apropriar em $77 \%$. Em relação ao decréscimo, destaca-se a conta de obrigações com fornecedores e prestadores de serviços que reduziu $59 \%$.

Os índices financeiros são de grande importância para podermos comparar e investigar as diferentes informações sobre as mais diversas empresas, esses índices ajudam a interpretar os resultados financei- 
ros. Com os índices, de certo modo podemos falar em uma só linguagem e assim o investidor pode tomar a melhor decisão sobre o seu capital.
Na tabela 2 está demonstrado os índices financeiros calculados com base nos balanços contábeis da Cooperativa X entre anos de 2012 e 2014.

Tabela 2 - Indicadores financeiros da Cooperativa X entre os anos de 2012 e 2014.

\begin{tabular}{lccc}
\hline \multicolumn{1}{c}{ Indicador } & $\mathbf{2 0 1 2}$ & $\mathbf{2 0 1 3}$ & $\mathbf{2 0 1 4}$ \\
\hline ROE & $\mathrm{R} \$ 0,15$ & $\mathrm{R} \$ 0,14$ & $\mathrm{R} \$ 0,12$ \\
\hline ROA & $\mathrm{R} \$ 0,08$ & $\mathrm{R} \$ 0,08$ & $\mathrm{R} \$ 0,06$ \\
\hline Margem líquida & $\mathrm{R} \$ 0,06$ & $\mathrm{R} \$ 0,06$ & $\mathrm{R} \$ 0,05$ \\
\hline Margem operacional & $\mathrm{R} \$ 0,17$ & $\mathrm{R} \$ 0,16$ & $\mathrm{R} \$ 0,16$ \\
\hline Grau de alavancagem financeira & 1,82 & 1,85 & 1,91 \\
\hline Liquidez corrente & 1,79 & 1,65 & 1,71 \\
\hline Liquidez imediata & 0,28 & 0,28 & 0,47 \\
\hline Participação de terceiros & $50,63 \%$ & $52,45 \%$ & $48,02 \%$ \\
\hline Composição do endividamento & $60,72 \%$ & $62,22 \%$ & $60,56 \%$ \\
\hline
\end{tabular}

O retorno sobre ativos (ROA) demonstra que os ativos proporcionam uma margem pequena para seus cooperados, a cada $\mathrm{R} \$ 1,00$ investido está rendendo $\mathrm{R} \$ 0,06$ para seus cooperados no ano de 2014. A rentabilidade do capital próprio (ROE) é quanto os cooperados estão tendo de lucro para sua cota investida, de acordo com a sua participação na cooperativa que é rateado depois com a sua proporcionalidade. A cada $\mathrm{R} \$ 1,00$ de investimento os cooperados tiveram $\mathrm{R} \$ 0,12$ de retorno no último ano.

A margem líquida demonstra quanto a cooperativa obtém de lucro para cada $\mathrm{R} \$ 1,00$ real que está entrando na comercialização de seus produtos, os resultados mostram que está sobrando apenas $\mathrm{R} \$$ 0,05 no ano de 2014, o que pode evidenciar que a mesma tem custos altos, impostos ou despesas que são onerosos para a empresa. A margem operacional, trata-se de quanto a empresa tem de resultado operacional para cada $\mathrm{R} \$ 1,00$ vendido, e a mesma apresenta um resultado de $\mathrm{R} \$ 0,16$ nos últimos dois anos, mostrando que a cooperativa tem grande volume de despesas operacionais.

No indicador do grau de alavancagem financeira (GAF), no ano de 2014 mostra que a empresa está alavancada 1,91 vezes, aumentando a sua rentabilidade, porém correndo um risco maior de insolvência, de não capacidade de honrar todos seus compromissos, pois a cooperativa está buscando rentabilidade através de endividamento.

$\mathrm{O}$ índice que evidencia a liquidez corrente demonstra que a empresa tem condições de honrar seus compromissos de curto prazo, pois a mesma tem capacidade de cobrir 1,71 vezes suas dívidas de curto prazo com seu ativo. Já a liquidez imediata, mostra que a empresa não consegue honrar seus compromissos com seu ativo imediato (caixa e aplicações de curto prazo), que podem se transformar em dinheiro antes de 90 dias, porque o indicador no ano de 2014 mostra que a cooperativa só consegue cobrir 0,47 vezes seu passivo de curto prazo.

Em 2012, 50,63\% do seu passivo total eram financiados pelo capital de terceiros, em 2013 para $52,45 \%$ e reduziu novamente para $48,02 \%$ em 2014 , tornando assim a cooperativa financiada tanto por terceiros quanto por capital próprio em proporções próximas.

No ano de 2013, 62,22\% eram dívidas de curto prazo, porém no ano seguinte esse percentual diminuiu, o que significa que a cooperativa tem menos contas para quitar dentro do exercício contábil, no qual o seu índice aponta que é de 60,56\%.

De um modo geral a cooperativa em estudo está bem financeiramente, porém, deve dar uma atenção maior à suas despesas para gerar mais benefícios a seus associados, o que ajudou também é a sua alavancagem financeira, contudo, deve atentar-se para que a cooperativa continue tendo uma adequada gestão financeira para ter condições de honrar seus compromissos sem grandes dificuldades. 


\section{Considerações finais}

Considerando que o objetivo do estudo era o a entendimento do modo de gestão financeira da cooperativa em estudo, podemos notar ao final o quão importante esta organização é para as famílias que vivem da agricultura na região Oeste de Santa Catarina. Por meio deste sistema cooperativo estas famílias puderam melhorar sua qualidade de vida, através da obtenção de benefícios proporcionados pelo modelo cooperativista.

$\mathrm{O}$ estudo buscou aprofundar a compreensão do modo de gestão da Cooperativa $\mathrm{X}$, tendo em vista que esta é referência quando se fala em sistemas cooperativos, dessa forma, buscou-se analisar os indicadores financeiros e saber como apresenta a situação financeira da organização. Para tal compreensão foram utilizados os índices de liquidez, onde mostra a capacidade da cooperativa em pagar suas dívidas a curto prazo. Os índices da estrutura de capital, o qual apresenta o quanto há de capital de terceiros financiando o ativo da cooperativa. $\mathrm{O}$ índice de rotação, onde mostra o ciclo de recebimento de dividendos. E por fim os índices de lucratividade e rentabilidade, os quais apresentaram os resultados financeiros obtidos.

Após a análise destes índices, concluiu-se que a organização tem uma administração financeira não conservadora, onde a mesma buscou investir em aplicações de curto prazo e bens intangíveis o que proporcionou a capacidade de financiar a cooperativa em muitas situações com capital próprio. Desta forma, pode-se perceber que a situação financeira da cooperativa é agradável, todavia, poderia realizar alguns ajustes em relação às despesas a fim de melhorar os resultados para os seus cooperados.

A obtenção de dados ficou restrita aos relatórios de gestão disponibilizado pelo site da organização devido à grandeza da estrutura da organização, o que dificulta o acesso às pessoas responsáveis para a captação de melhores informações. Apesar disso, foi possível obter dados suficientes para compreender como funciona a gestão de uma cooperativa de grande porte como a Cooperativa $\mathrm{X}$.

Como indicação de estudos a serem realizados futuramente, sugere-se a pesquisa comparativa utilizando outras cooperativas agropecuárias da região com o intuito de comparar os indicadores dessas empresas e diferenças encontradas na forma de gerir seus recursos financeiros.

\section{Referências}

BRAGA, Roberto. Fundamentos e técnicas de administração financeira. São Paulo: Atlas, 2011

BRITO, Francis Roberto; CARVALHO, Luciane; BRITO, Rosimeire Vieira Lima; CAMILO, Victor. Análise financeira de balanço financeiro da empresa Cocamar - Cooperativa Agroindustrial de Maringá. In: Revista de Ciências Empresariais Maringá Management. v. 9, n. 2, p. 39-48, 2012.

CARVALHO, Adriano Dias. O cooperativismo sob a ótica da gestão estratégica global. São Paulo: Baraúna, 2011.

FRANTZ, Walter. Associativismo, cooperativismo e economia solidária. Ijuí: Editora Unijuí, 2012.

GERHARDT, Tatiana Engel; SILVEIRA, Denise Tolfo. Metodologia de Pesquisa. Universidade Federal do Rio Grande do Sul. Porto Alegre: Editora da UFRGS, 2009. Disponível em: <http://www.ufrgs.br/cursopgdr/downloadsSerie/ derad005.pdf> Acessado em: 18/09/2014.

GIL, Antônio Carlos. Métodos e técnicas de pesquisa social. 6. ed. São Paulo: Atlas, 2008.

GOZER, Isabel Cristina; GIMENES, Régio Marcio Toesca; MENEZES, Emilio Araujo; GOZER, Diego Fornazier; GIMENES, Fátima Maria Pegorini. Avaliação econômico-financeira de cooperativas agropecuárias utilizando índicespadrão do setor: um estudo de caso. In: XLV Congresso da Sociedade Brasileira de Economia, Administração e Sociologia Rural. 2007.

LOPES, Abel Panerai. Análise de indicadores econômico-financeiros e sociais na gestão de cooperativas agropecuárias na região central do estado do rio grande do sul. 2009. 137 f. Dissertação de Mestrado em Extensão Rural - Centro de Ciências Rurais, Universidade Federal de Santa Maria, Santa Maria. 2009.

MARCONI, Marina de Andrade; LAKATOS, Eva Maria. Fundamentos da metodologia científica. 7. ed. São Paulo: Editora Atlas, 2010. 
MINISTÉRIO DA AGRICULTURA. Cooperativismo e associativismo. Disponível em: $<$ http://www.agricultura.gov.br/cooperativismoassociativismo> Acessado em: 26/09/2014.

OCB. Cooperativismo: forma ideal de organização. Disponível em: <http://www.ocb.org.br/site/cooperativismo/> Acessado em: 26/09/2014.

OCB. Evolução no Brasil: movimento livre da influência do Estado. Disponível em: <http://www.ocb.org.br/site/cooperativismo/evol ucao_no_brasil.asp> Acessado em: 26/09/2014.

OCB. Forma ideal de organização. Disponível em: <http://www.ocb.org.br/site/cooperativismo/inde x.asp>. Acessado em: 4/11/2014.

OLIVEIRA, Djalma de Pinho Rebouças de. Manual de gestão das cooperativas: uma abordagem prática. 5 ed. São Paulo: Atlas, 2011.

PRODANOV, Cleber Cristiano; FREITAS, Ernani Cesar de. Metodologia do trabalho científico: Métodos e Técnicas da Pesquisa e do Trabalho Acadêmico. 2. ed. Novo Hamburgo: Feevale, 2013.

ROSS, Stephen A.; WESTERFIELD, Randolph W.; JORDAN, Bradford D. Administração financeira. McGraw Hill Brasil, 2011.

SCHMIDT, Derli; PERIUS, Vergílio. Cooperativismo e cooperativa. In: CATTANI, Antonio David. (Org). A outra economia. Porto Alegre: Veraz, 2003.

VERGARA, Sylvia Constant. Projetos e Relatórios de Pesquisa em Administração. 14 ed. São Paulo: Atlas, 20 